\title{
a economia e as concepções econômicas no egito faraônico: síntese de alguns debates
}

\author{
Ciro Flamarion Cardoso \\ Centro de Estudos Interdisciplinares da Antigüidade - UFF
}

\section{RESUMO}

$\mathrm{O}$ artigo resume os debates entre diferentes correntes interpretativas da economia do Egito faraônico - marxista, polányiana (substantivista) e formalista - tal como ocorreram a partir da década de 1970. A seguir, o Autor apresenta suas próprias opiniões a respeito, no essencial opostas às concepções formalistas, com ênfase na problemática do trabalho, com relação à qual são expostos enfoques baseados em pesquisa original.

Palavras-chave: egiptologia, modo de produção asiático, substantivismo, formalismo, trabalho.

\begin{abstract}
This article presents a synthesis of discussions opposing contrasting interpretations concerning the economy of pharaonic Egypt - marxist, Polányian (substantivism) and economic formalist - , presented since about 1970.The Author next develops his own opinions, contrary to the economically formalist views of ancient societies. This is done by emphasizing labor as an economic factor, with regard to which some analyses based on original research are presented.
\end{abstract}

Key words: egyptology, asiatic mode of production, substantivism, formalism, labor.

Em 1995, coube a Edward Bleiberg a tarefa de redigir um artigo que resumisse os conhecimentos disponíveis acerca da economia do Egito faraônico, numa coleção que sintetizava, em quatro tomos, o que se sabia sobre o antigo Oriente Próximo. (Bleiberg, 1995) O artigo em questão é extremamente cauteloso em suas afirmações e generalizações, equilibrado em seusjulgamentos... e sua leitura dá a desconfortável sensação de ser muito pouco o que sabemos com segurança a respeito do assunto!

O texto de Bleiberg mostra também que tal campo de estudos, devido a um quase desaparecimento do marxismo nos debates do momento, algo que parece ter acontecido em meados da década de 1980, acha-se 
atualmente dividido em dois campos, cujas opiniões no tocante à lógica da economia do Egito faraônico são opostas. De um lado, situa-se um especialista como Morris Silver, que pode ser classificado como um "formalista" — isto é, defensor da opinião segundo a qual as teorias econômicas geradas desde o século XVIII em função do capitalismo seriam aplicáveis a todas as sociedades de todas as épocas - achando, naturalmente, que uma lógica econômica semelhante à moderna regia a economia egípcia como rege o capitalismo contemporâneo: conceitos como mercado, lucro ou capital poderiam, portanto, aplicar-se àquela tanto quanto a este. (Silver, 1986:97-193) Do outro lado, os seguidores de Jacob J. Janssen, que muitos consideram ser o fundador de uma história econômica teorizada do antigo Egito, numa linha derivada de Karl Polányi, enxergam uma economia cuja lógica está incrustada no social, e que não pode, nem deve ser estudada a partir dos conceitos forjados pela ciência econômica nos últimos duzentos e poucos anos. (Janssen, 1982)

Cada grupo possui suas idiossincrasias e excessos. Silver tende a generalizar indevidamente dados provenientes de períodos em que, enfraquecido o Estado centralizado e seus sistemas redistributivos, as atividades privadas muito naturalmente passaram ao primeiro plano, e também a considerar que na velha economia egípcia existia uma lógica moderna demais. Os polányianos, por sua vez, em casos extremos negam qualquer lógica verdadeiramente econômica nas sociedades antigas. Houve, ainda, tentativas - a me u ver mal sucedidas - de conciliação entre a corrente polanyiana e a formalista. (Snell, 1997: 156-8)

\section{Os debates acerca da antiga economia egípcia desde a década de 1970}

A egiptologia é uma disciplina bastante tradicional, infensa em muitos casos ao debate teórico. Por outro lado, ela se dedica muito mais - em parte pela natureza da maior parte das fontes que se conservaram - a estudos da monarquia faraônica e da religião do que, por exemplo, da economia. Mesmo assim, a partir da década de 1970, houve debates sobre a economia egípcia, animados por três perspectivas principais: 1) o marxismo, através de uma retomada da noção de modo de produção asiático (que muitos preferem chamar por nomes diferentes, que não sejam de base geográfica: modo de produção tributário-aldeão, por exemplo), uma corrente que esteve muito mais presente nas discussões até meados da década de 1980, esfumando-se bastante a seguir; 2) o 
substantivismo (ou realismo) derivado de Polányi; e 3) o formalismo - isto é, a crença na possibilidade de explicar a antiga economia dos egípcios mediante teorias e conceitos elaborados pela ciência econômica desde o século XVIII em função do capitalismo.

\section{O marxismo italiano}

Nas décadas de 1970 e 1980, autores italianos, com destaque para Mario Liverani e Cario Zaccagnini, partindo da noção marxista de modo de produção asiático e sob forte influência das idéias de Sabatino Moscati (Moscati, org., 1976) ocuparam-se das estruturas do antigo Oriente Próximo (incluindo as do Egito) na fase posterior à urbanização ocorrida em várias de suas regiões. A originalidade de seus estudos foi dupla em relação à grande onda de interesse pelo modo de produção asiático de parte dos marxistas da década de 1960 , em função dos debates acerca de ser a evolução das sociedades humanas unilinear ou multilinear. Em primeiro lugar, nesta discussão mais antiga era pouco comum o uso extenso de documentação primária: Liverani e Zaccagnini, pelo contrário, são especialistas da história próximo-oriental antiga e bons conhecedores de suas fontes. A outra especificidade é que viram tal modo de produção como estando constituído pela articulação, nu ma mesma estrutura (em termos marxistas, em uma mesma formação econômico-social), de dois modos de produção distintos, que chamaram de "modo de produção doméstico" (ou aldeão) e "modo de produção palaciano".

O primeiro seria uma forma de organização social cuja origem remonta ao Neolítico: economia de subsistência; ausência de divisão e especialização do trabalho, dando-se em cada aldeia a união da agricultura e do artesanato; inexistência de uma diferenciação em classes sociais, se bem que as aldeias já não fossem de todo igualitárias; na Ásia ocidental (mas não no Egito), sobrevivência por algum tempo, em fase já histórica, de restos da propriedade comunitária (coletiva) da terra.

O "modo de produção palaciano" seria um efeito da própria urbanização, que resultou no surgimento de complexos palacianos e templários como centro de uma nova organização econômico-social.A economia palaciana, cujo centro era urbano, baseava-se na concentração, transformação e redistribuição dos excedentes extraídos pelos templos e palácios aos produtores diretos - em sua maioria, camponeses residentes, ainda, em comunidades aldeãs - mediante coação fiscal, isto é, a exigência da "corvéia real" (trabalhos forçados, embora remunerados em 
rações, exigidos rotativamente, por tempo limitado, aos aldeães) e de tributos in natura. A economia palaciana manifestava divisão e especialização do trabalho, com a existência de especialistas de tempo integral (artesãos tanto quanto sacerdotes, burocratas, mais tardiamente soldados profissionais) dependentes de templos e palácios, uma diferenciação fortemente hierárquica da sociedade, um sistema complexo de propriedade que incluía a propriedade estatal (dos templos e palácios) mas, também, formas privadas (seja de função, seja familiares e hereditárias) de apropriação.

As comunidades aldeãs, vistas em si mesmas, apareceriam como resíduo de um modo de produção originado no Neolítico: mas agora eram, ao mesmo tempo e principalmente, a base sobre a qual o novo modo de produção se desenvolvera e podia se reproduzir. Com efeito, o modo de produção palaciano só pôde aparecer e se expandir mediante a exploração do modo de produção mais antigo, que foi subordinado, modificado e adaptado aos novos interesses, mesmo sem perder todas as suas características específicas. (Zaccagnini, 1981;Liverani, 1976;Liverani, 1983)

No Brasil, esta retomada do conceito de modo de produção asiático sobre novas bases refletiu-se em diversos trabalhos de minha autoria e num livro por mim coordenado. (Cf. p. ex. Cardoso, 1986.b; Cardoso, org., 1990) Veremos que, em escritos posteriores, Liverani e Zaccagnini desenvolveram raciocínios, no tocante às relações de troca entre os Estados próximo-orientais da Época do Bronze, derivados de noções polányianas.

\section{À sombra de Polányi}

Polányi chama "formal" a visão da economia que decorre da consideração de um caráter lógico — e, não, empírico ou histórico — da relação existente entre meios e finalidades: a economia seria, neste caso, uma escolha racional entre alternativas aplicadas a recursos escassos. Uma das conseqüências de uma visão desse tipo é que, para os formalistas, todas as sociedades humanas, as do passado tanto quanto as do presente, poderiam explicar-se pela teoria econômica surgida, a partir do século XVIII, com os fisiocratas e sobretudo com a Escola de Manchester da Economia Política. Pelo contrário, a visão do próprio Polányi insiste na definição da economia como atividade institucionalizada de interação entre os seres humanos e o meio ambiente, com a finalidade de acionar os recursos naturais para satisfazer suas necessidades. Esta forma de ver 
resulta em constatar a existência de formas diferentes de institucionalização da economia nas sociedades humanas e, portanto, na necessidade de estudar o lugar da economia em diferentes sociedades como algo mutável. Neste caso, as sociedades antigas apareceriam como tendo uma economia "incrustada" (submersa, integrada) no social. (Polányi et al, orgs., 1976)

Em seu livro de 1975 sobre os preços no período dos Ramsés (grosso modo o período que vai do século XIII ao início do século XI a.C, englobando as dinastias egípcias XIX e XX), Jacob Janssen, ao proceder a um estudo detalhado dos preços e suas flutuações na época ramséssida, fez algumas generalizações macroeconômicas de base claramente polányiana. Segundo ele, inexistia, no Egito antigo, o "mercado", no sentido de um mecanismo formador de preços por oferta e procura. A estrutura macroeconômica do Egito teria sido a de um campesinato auto-suficiente dominado pelo palácio e pelos templos (constituindo um problema ainda não solucionado a indagação acerca de integrarem ou não os palácios e templos uma mesma organização). O conjunto funcionaria a partir da concentração e posterior redistribuição de excedentes; se a concentração se fazia à base de tributos (impostos) ou da renda da terra seria outro ponto também ainda inseguro. Seja como for, inexistia, em tal conjunto, um lugar para um verdadeiro mercado, por mais que ocorressem, sem dúvida, compras e vendas por escambo (troca de mercadoria por mercadoria) - havendo no entanto uma moeda de conta - nas quais a busca do lucro comercial não estava ausente: mas, estas trocas e o lucro desempenhavam um papel limitado. Analogamente, inexistia um mercado de força de trabalho. (Janssen, 1975)

Em 1982, num artigo que teve maior difusão e provocou mais debates teóricos de caráter geral do que o livro de 1975, Janssen expôs em maior detalhe sua forma (derivada da teoria de Polányi) de entender as estruturas do Egito dos farás. Distinguiu um setor urbano - que concentrava provavelmente o sistema redistributivo em favor de funcionários, sacerdotes, militares, artesãos altamente especializados, etc. 一, representando uma espécie de cume ou superestrutura que repousava sobre outro setor muito mais vasto, explorado tributariamente pelo primeiro: uma sociedade camponesa composta por unidades domésticas tendencialmente auto-suficientes. Aqueles bens que o setor camponês não produzia (por exemplo: sal, artigos de metal, produtos de luxo) podiam chegar-lhe, eventualmente, por meio da redistribuição estatal,já que a "corvéia real", por exemplo, apesar de obrigatória, dava lugar a remunerações mediante distribuição de rações em produtos. 
Podiam também ser adquiridos por escambo. Mas, neste tipo de sociedade, o papel do mercado era forçosamente periférico. Um terceiro modo de adquirir certos bens seria o dos dons e contra-dons entre as famílias de uma mesma comunidade, num sistema de reciprocidade. A economia, nessas condições, é difícil de distinguir da sociedade como um todo (na qual está "incrustada"): ela funciona como um subproduto tanto do parentesco quanto de obrigações políticas e religiosas. (Janssen, 1982)

De forma bem menos explícita no tocante à teoria do que naqueles vistos até aqui, outros trabalhos de grande interesse, bem apoiados nas fontes primárias egípcias, surgidos paralelamente àqueles já mencionados - para dar um exemplo, os textos da egiptóloga Bernadette Menu -, iam no mesmo sentido: um sentido que, em linhas gerais, pode ser chamado de substantivista. Isto por advogarem uma visão específica (e institucional) para as estruturas do antigo Egito, em lugar de aceitarem uma projeção sobre a sociedade egípcia de estruturas mais recentes. (Menu, 1982)

Mencionaremos agora as interpretações de base polányiana avançadas, no tocante às trocas de bens no Oriente Próximo, por Zaccagnini e Liverani, autores italianosjá mencionados antes num outro contexto.

O período tardio da Idade do Bronze foi marcado, em seu apogeu, por um relativo equilíbrio internacional: havia certo número de reinos importantes, nenhum deles capaz de dominar os outros; destes, o do Mitanni foi o único, durante tal período, a perder importância em caráter absoluto. Seja como for, no século XIV a.C., época iluminada pelo arquivo de Amarna - egípcio mas redigido na língua das relações internacionais da época, o acadiano-, aparecem tratados como grandes reis os do Egito, da Babilônia, da Assíria, do Mitanni, do Khatti (reino hitita), de Arzawa (reino da Ásia Menor, a oeste do dos hititas) e de Chipre. No tocante à correspondência amarniana dos grandes reis entre si, confrontada às inscrições reais da mesma época (estas destinadas ao público interno de cada rei), Cario Zaccagnini propõe as observações seguintes (Zaccagnini, 1987: 61):

\begin{tabular}{ccc}
\hline Nível factual & \multicolumn{2}{c}{ Interpretação ideológica } \\
& Ênfase na redistribuição & Ênfase na reciprocidade \\
\hline $\begin{array}{c}\text { Transferência de objetos } \\
\text { Inventários }\end{array}$ & $\begin{array}{c}\text { Contribuições forçosas } \\
\text { Inscrições reais }\end{array}$ & $\begin{array}{c}\text { Dom/contra-dom } \\
\text { Cartas }\end{array}$ \\
\hline
\end{tabular}


A forma do quadro acima deixa a desejar, mas o que se quer mostrar por meio dele é o seguinte: na correspondência amarniana, os inventários se refeririam às transferências de objetos entre as cortes, ao se encarar empiricamente tais trocas como listas do que era enviado. Quanto às maneiras em que a ideologia daquela época "traduzia" ou dava forma textual àquelas transferências, no entanto, haveria uma divergência entre as cartas (incluídas, como os inventários, no arquivo de Amarna) dos grandes reis entre si, nas quais as trocas de objetos, às vezes em enormes quantidades, apareciam caracterizadas como dons e contra-dons ("presentes"), e as inscrições reais destinadas à população de seu próprio reino, em que as mesmíssimas transações apareciam sob a forma de "tributos" pagos pelos monarcas estrangeiros. Mesmo os inventários, no entanto, implicavam conotações ideológicas.

A ideologia que está por trás da correspondência entre os grandes reis baseia-se em descrever cada reino como se fosse uma "casa" (no sentido do termo inglês household), com o respectivo rei como chefe de uma família extensa que compreendia todo o reino. Estes grandes reis tratam-se de "irmãos" e, nessa qualidade, trocam presentes entre si. As quantidades às vezes surpreendentemente elevadas de bens que circulavam desta maneira mostram que o fato de chamá-los de "presentes" era simplesmente a moldura ideológica convencionada para caracterizar uma boa parte, se não a maioria, das trocas que abasteciam os diferentes reinos em matérias-primas diversas e artigos de luxo. A ética dessa correspondência levava a que se salientasse o caráter bilateral exclusivo da relação entre reis (estes entravam em contacto dois a dois, com exclusão de um terceiro qualquer; embora na prática, em paralelo, cada um dos correspondentes também se relacionasse bilateralmente com o terceiro em questão) e o valor de uso, não o de troca, dos bens que circulavam de um sistema palaciano a outro. Ao mesmo tempo, era um artifício retórico corrente a depreciação dos bens recebidos, seja alegando que não correspondiam às promessas feitas antes de seu envio, seja afirmando que tais bens eram excessivamente abundantes no país de origem e, portanto, o rei que os estava enviando deveria ter sido mais generoso no tocante às quantidades mandadas.Vamos exemplificar estes diferentes elementos com a correspondência de Amarna; é bom salientar, porém, que a documentação relativa ao período posterior que corresponde ao apogeu raméssida (o século XIII a.C.) apresenta exatamente as mesmas características estruturais no relativo à ideologia da correspondência e das trocas entre grandes reis. (Zaccagnini, 1987) 
Eis aqui o preâmbulo de uma carta de Amenhotep III a Kadashmanenlil I da Babilônia:

Assim (fala) Nibmuareya [= Nebmaatra, nome de trono do faraó C.F.C.J, Grande Rei, rei do Egito. Dize a Kadashmanenlil, o rei de Karaduniash $[=$ Babilônia $]$, meu irmão: Tudo vai bem para mim. Que tudo possa ir bem para ti. Que tudo possa ir bem para tua casa, tuas esposas, teus filhos, teus nobres, tuas tropas, teus cavalos, teus carros de guerra; e em teus territórios. Quanto a mim, tudo vai bem. Tudo vai muito, muito bem quanto a minha casa, minhas esposas, meus filhos, meus nobres, minhas tropas numerosas, meus cavalos, meus carros de guerra; e em todos os meus territórios. (Moran, 1992: 10)

Ou seja: um "irmão" dá notícias de sua própria "família" (seu reino) a outro "irmão", seu igual, e pergunta-lhe acerca da sua "família" (do seu reino). Há alguma variação de forma no arquivo quanto a isto, mas não no tocante a características essenciais.

O rei de Babilonia, Burraburiash II, tendo sido informado de que o rei assírio enviara pela primeira vez embaixadores e presentes ao do Egito, escreveu a este último:

Agora, no tocante a meus vassalos assírios, não fui eu quem tos enviei. Por que vieram a teu país por decisão própria? Se me amas, eles nada conseguirão. Envia-os a mim com as mãos vazias. Eu te envio, como presente de saudação, três minas de genuíno lápis-lazúli e cinco parelhas de cavalos para cinco carros de guerra de madeira. (Moran, 1992: 18)

Esta passagem, precedida na carta pela recordação de, no passado, ter recusado entrar em relações com os canaanitas contra o Egito, ilustra o caráter somente bilateral que em teoria deveriam ter as relações entre grandes reis (daí "se me amas, eles nada conseguirão"). Por outro lado, era malvisto que um grande rei entrasse em relação direta com o vassalo de um outro: assim, o rei da Babilônia afeta ser o suserano do da Assíria - o que não era verdadeiro, tratando-se unicamente de um artifício discursivo. "Presente de saudação" era a maneira habitual de chamar os dons reais.

Em outra missiva, afirmava Burraburiash II: 
Outrossim, no país de meu irmão, dizem-me, tudo está disponível, e meu irmão de nada absolutamente tem necessidade. Outrossim, no meu país tudo está disponível e, de minha parte, nada absolutamente necessito. (No entanto), nós herdamos boas relações que existem há muito de reis (do passado), de modo que deveríamos enviar saudações [entenda-se: presentes de saudação - C.F.C.] um ao outro. Estas boas relações é que serão duradouras entre nós. (Moran, 1992:13)

Em outras palavras, as trocas de presentes não têm finalidades mercantis, é o que significa o texto: dão-se somente para garantir boas relações entre reis que são tradicionalmente "irmãos". No entanto, em muitos casos tais trocas envolvem grandes quantidades de bens e, como depois veremos, complementaridade de abastecimento entre áreas produtivas distintas.

A ausência alegada de motivação mercantil nas trocas leva a que, ao solicitar o envio de determinados bens, se dê uma razão ad hoc para tanto, ligada a o seu uso, com freqüencia sem entrar em maiores detalhes sobre o que se afirma. Aqui está um exemplo tirado de carta de Ashshuruballit I da Assíria ao faraó (Moran, 1992: 39): "Eu estou ocupado na construção de um novo palácio. Envia-me todo o ouro necessário para seu adorno". Numa carta, provavelmente de Kadashmanenlil I de Babilônia a Amenhotep III (Moran, 1992:9), o rei asiático declarava que, se o faraó demorasse a enviar-lhe o ouro de que precisava para "terminar a obra em que estou ocupado", de nada serviria enviá-lo depois. Neste caso, a relação necessária de reciprocidade (dom/contradom) é também salientada: o rei mesopotâmio prometera uma filha sua em matrimônio ao faraó, mas escreveu que, se o ouro chegasse estando a obrajá terminada, "eu to devolveria e não te daria minha filha em cas amento".

A depreciação do recebido é constante nos documentos de Amarna. Uma de suas formas habituais é ilustrada quando lemos, numa cartajá citada (Moran, 1992:39), o rei assírio dizer ao do Egito que o ouro que este lhe enviara "nem mesmo basta para cobrir as despesas de meus mensageiros na viagem de ida e na de volta". A outra aparece na afirmação, sempre na mesma carta, de que "o ouro em teu país é (como) o pó: basta recolhê-1o". Bastante freqüente, também, é a comparação da generosidade dos antecessores (ou do mesmo soberano no passado) com a parcimônia do rei atual de um dado país. Por exemplo, assim escreveu Tushratta do Mitanni a Amenhotep III (Moran, 1992:44):"Tu 
enviaste muito ouro ao meu pai. Enviaste-lhe grandes vasos e jarrões de ouro. Enviaste-1he tijolos de ouro como se fossem o mesmo que (tijolos de) cobre".

Os presentes entre reis podiam incluir, entre outras coisas, mulheres das famílias reais dadas em casamento a outros reis (com a exceção do Egito, que recebia princesas estrangeiras mas não enviava as suas: $f$. sobretudo Moran, 1992: 8-9)' — e cujo envio dava origem a trocas muito copiosas de presentes preciosos (como preço da noiva numa direção, dote na outra) —, minérios (ouro,prata, cobre), madeira, tecidos finos, artigos e objetos de arte confeccionados com materiais preciosos (ouro, prata, marfim, etc.), carros e cavalos de guerra (sendo, estes, elementos essenciais da tecnologia militar do período), ungüentos e perfumes. No caso do Egito, que detinha o monopólio das extrações de ouro mais produtivas do Oriente Próximo (na Núbia e no deserto oriental) e de suas rotas, era sobretudo tal metal precioso, em grande quantidade, o que pediam os reis de outros países. Comojá se disse, os inventários de presentes enviados podiam chegar a ser espantosos no tocante ao volume enorme de riquezas que representam (ver, por exemplo, Moran, 1992: 24-6, 27-34, 51-7).

De certo modo, entravam na mesma lógica os pedidos de envio de mão-de-obra (serviçais) e especialistas: médicos, mágicos, escultores, etc. Neste caso, tratava-se de um empréstimo: passada a necessidade alegada (sempre de acordo com a lógica do "valor de uso", portanto), o membro do pessoal de outro palácio emprestado seria devolvido. De forma análoga, estátuas divinas a que se atribuíam poderes curativos podiam circular entre as cortes.

Em importante artigo de síntese (embora negue que se trate disto), Mario Liverani tratou de identificar os principais traços do sistema de trocas da fase tardia do Bronze no Oriente Próximo, com ênfase no caso da Síria.Tais trocas se efetuavam no nível político mais alto (o do palácio). Os mercadores, mensageiros, prospectores de minas, etc, eram despachados pelos palácios, mesmo quando também efetuassem atividades em proveito próprio. Cada grande rei podia contactar seus vassalos, reis menores em sua própria área de influência, ou outros grandes reis:

A legitimidade de cada novo rei passava com freqüência, no Egito, pelo casamento com uma princesa de sangue real. Não era incomum o casamento do pai com a própria filha (foi o caso de Amenhotep III com Sitamon) como esposa secundária, já que podia ser perigoso deixar uma princesa disponível. Com maior razão, não eram aceitas propostas de casamento vindas do exterior do País. 
mas um grande rei não deveria entrar em contacto direto com o vassalo de outro. Em conseqüência disso, as relações de troca de longa distância se fragmentavam em etapas correspondentes aos diferentes sistemas palacianos, as quais não podiam ser evitadas ou contornadas; e as atividades propriamente mercantis (e vistas como tais) ficavam limitadas, bem como os sistemas de rotas terrestres e marítimas, embora tal ocorresse também por deficiências técnicas. (Liverani, 1987)

As rotas marítimas na época tardia do Bronze no Oriente Próximo achavam-se fragmentadas, bem como a navegação em si. Havia uma frota egípcia, frotas das cidades costeiras da Síria-Palestina, outras de Chipre (Alashia), de Ura (na Cilícia) e de diversas cidades micênicas. A presença dos grandes sistemas palacianos limitava - em conjunto com características da tecnologia naval da época - a possibilidade de uma navegação realmente de longo curso.

No tocante às reclamações relativas às trocas, um grande rei, a o receber um pedido de algum súdito nesse sentido, devia entrar em contacto com o grande rei em cuja área de influência ocorrera o incidente: este último, por sua vez, transmitiria a queixa ao governante vassalo em cujo território acontecera a coisa; e o vassalo por vezes responsabilizava a aldeia mais próxima à ocorrência, que então arcaria com o ônus das compensações. Os grandes reis também intercediam junto a outros grandes reis por seus mensageiros: um dos modos de mostrar desfavor consistia em reter os mensageiros de outro monarca por tempo mais longo do que o necessário para completar sua missão.

Eis aqui, numa carta de Burraburiash II da Babilônia a Akhenaton, a ilustração de ambas as situações:

... meus mercadores, que estavam a caminho com Akhutabu [mensageiro, ou seja, embaixador do rei mesopotâmio - C.F.C.], foram detidos em Canaã devido a assuntos de negócios. Depois que Akhutabu foi ter com meu irmão [ou seja, com o faraó - C.F.C.],em Khinnatuna de Canaã, Shumadda, o filho de Balumme, e Shutatna, o filho de Sharatum de Akka, tendo enviado seus sequazes, mataram meus mercadores e roubaram o seu dinheiro. (...) Pergunta-lhe [há uma lacuna no documento, mas o "lhe" parece referir-se ao rei da cidade-Estado de Akka - C.F.C.] para que te informe. Canaã é país teu e seus reis são teus servidores. Eu fui despojado em teu país. Faze com que sejam responsabilizados e compensem pelo dinheiro que roubaram. Mata os homens que mataram meus servidores: eles matara de novo, seja uma caravana minha ou teus próprios mensageiros, por conse- 
guinte o fluxo de mensageiros entre nós será cortado. E mesmo que tentem negar-te isto, Shumadda, tendo bloqueado a passagem de um de meus homens, reteve-o em sua companhia e outro homem, tendo sido forçado a servir Shutatna de Akka, continua a servi-lo. Estes homens deviam ser-te enviados para que possas investigar, inquirir se eles estão mortos [isto é, se os dependentes do rei da Babilonia detidos em Akka estão vivos ou mortos - C.F.C.] e assim ficar informado. Como presente de saudação, mando-te uma mina de lápis-lazúli. Despacha meu mensageiro imediatamente, para que eu conheça a decisão de meu irmão. Não detenhas meu mensageiro. Deixa-o vir ter comigo imediatamente. (Moran, 1992:16-7)

As cartas de Amarna mostram que, apesar do que se disse sobre as estruturas das trocas na época tardia do Bronze, a idéia do comércio e a do lucro estavam abrindo caminho em certas áreas. É o caso, por exemplo, de Ugarit.Vamos ilustrar tal fato com elementos da correspondência do rei de Chipre (Alashia) com o faraó egípcio.Tal correspondência se adequa em geral à ideologia do dom/contra-dom, mas apresenta também elementos discrepantes. Por exemplo, eis aqui duas passagens curiosas de uma mesma carta:

Outrossim, meu irmão, homens de meu país falam-me repetidamente de minha madeira que o rei do Egito recebe de mim. Meu irmão, entrega-me o pagamento devido. (...)

Tu não foste colocado (no mesmo nível) do rei de Khatti ou do rei de Shankhar. Qualquer presente de saudação que (meu irmão) me enviar, eu de minha parte enviar-te-ei em troca o dobro. (Moran, 1992:107)

Em ambas as passagens, a linguagem é muito mais mercantil do que a habitual nos documentos de Amarna, mesmo se ao mesmo tempo se usa a expressão usual "presente de saudação".

Em outra carta do rei de Chipre pode-se ler:

Estes homens são meus mercadores. Meu irmão, deixa-os ir em segurança e prontamente. Ninguém deve, exigindo algo em teu nome, aproximar-se de meus mercadores ou de meu barco. (Moran, 1992: 112)

O que temos aqui é simplesmente um pedido ao mesmo tempo de salvo-conduto e de isenção de impostos alfandegários (ou de qualquer 
outro tipo) para o comércio de Chipre com o Egito, numa lógica que contraria a estrutura mesma do comércio marítimo fragmentado típico do auge dos sistemas palacianos próximo-orientais.

Terminando este tópico, mencionemos a pertinente observação de Liverani sobre a tendência a uma complementaridade entre diferentes áreas do Oriente Próximo nas trocas, devido à concentração regional exclusiva, ou muito majoritária, de certas produções mais importantes. Assim, a Síria-Palestina se especializava em azeite de oliva, madeira e tecidos tingidos de púrpura; o cobre tinha duas zonas referenciais de maior peso: a ilha de Chipre a oeste e, a leste, a região do Golfo Pérsico (Omã-Magan); o caso do estanho é menos claro, mas pareceria que o Irã em certos períodos era a zona de referência; o Egito controlava as rotas do ouro, bem com as do incenso e da mirra do país de Punt (nesta época proavelmente a Somália e talvez também o sul da Arábia) por sua navegação no mar Vermelho; por fim, o lápis-lazúli vinha do atual Afeganistão. (Liverani, 1987: 68) Um de tais circuitos comerciais, dentro do que já vimos acerca da fragmentação dos contactos a longa distância, é representado pelas rotas (fluviais e marítimas) controladas pelo Egito no tocante ao comércio de ouro e incenso.

\section{A vertente formalista}

As opiniões de Barry J. Kemp, que abordaremos agora, configuram uma visão formalista de tipo especial, distinta de um formalismo que poderíamos chamar "ortodoxo", ou clássico, como o que achamos em outros autores, por exemplo o já mencionado Morris Silver. Tal visão lhe permite ter o que Polányi chama de visão formal da economia sem, por isto, negar a existência de especificidades na economia do antigo Egito, caso que estuda, a ser comparada com as economias do presente.

A egiptologia funciona majoritariamente em circuito fechado. Assim sendo, Liverani e Zaccagnini, especialistas, não no antigo Egito (embora muitas vezes também o considerassem em suas teorizações) mas, sim, em sociedades antigas do oeste da Ásia, tiveram seus trabalhos, já mencionados, amplamente ignorados pelos egiptólogos.JacobJanssen, no entanto, era um egiptólogo de prestígio: suas idéias provocaram uma resposta de peso, na forma de um o livro que Barry Kemp publicou em 1989.

Nessa resposta de Kemp, configura-se um novo tipo de formalismo: novo porque não consiste em projetar ao passado as categorias da 
moderna economia capitalista de mercado como se fossem universais mas, sim, em sustentar que tanto as economias antigas (entre elas, a egípcia) quanto as modernas e contemporâneas se caracterizam pela copresença, em proporções variáveis, de duas esferas. Uma é a esfera pública e administrada. Hoje em dia, mesmo nas economias mais capitalistas e voltadas para o mercado, ela aparece em coisas como economia de guerra e contratos militares, subsídios aos preços agrícolas, seguridade social, pagamentos aos desempregados, controle exercido pelos governos sobre o sistema monetário e financeiro (emissão mais ou menos abundante de moeda e manipulação das taxas dejuros, por exemplo). A esfera pública provê uma espécie de moldura dentro de cujos limites pode funcionar a outra esfera, isto é, a economia de mercado, vinculada à procura e aos interesses privados.

Já em trabalho anterior, Kemp tendia a conceder grande importância ao setor privado e aos mecanismos do mercado na economia egípcia, até mesmo em pleno III $^{\circ}$ milênio a.C:

... o registro arqueológico sugere um complexo e extenso sistema de comercialização que, ocasionalmente, satisfazia até mesmo um gosto pelos artigos exóticos importados através da produção de imitações, o que torna difícil aceitar que fosse de responsabilidade integral, ou mesmo majoritária, de um sistema redistributivo fechado, governamental. (Kemp, 1983: 81)

O sexto capítulo do livro de 1989 do autor que analisamos tem por título "o nascimento do homem econômico". Nele, Kemp trata de apresentar em detalhe a sua opinião: os antigos egípcios, mesmo não possuindo conhecimento algum da economia como disciplina abstrata ou teórica, agiam intuitivamente como o famoso homo oeconomicus. Eis aqui como sintetiza seu argumento:

... o antigo Egito era, para os padrões do mundo antigo, um país rico. Em tempos estáveis, tinha riqueza em quantidade, em estoque e em circulação, oferecendo a todos a possibilidade ou o sonho de uma vida muito acima do nível de subsistência. Isto criava o fenômeno da demanda privada, poderoso e amplamente difundido a partir do fim do Período Pré-Dinástico [ $I V^{o}$ milênio a. C. - C.F.C.]. Quando o Estado era forte e bem organizado, muitas pessoas obtinham muito de seus mecanismos redistributivos, que, ao mesmo tempo, devem ter agido como um controle geral sobre a economia inteira 
simplesmente devido à sua magnitude. Mas o mercado é que respondia àquelas demandas que não pudessem ser atendidas por entregas do Estado (e, em épocas de governo fraco, isto significaria virtualmente tudo). (...) Os valores sociais obscureciam a realidade do processo, ocultando o conceito de lucro. Mas qualquer egípcio antigo que pudesse sentir a diferença entre um bom preço e um mau preço era um fepresentante do "homem econômico". (Kemp, 1989: 259)

Sigamos ainda a argumentação de Kemp:

Podemos dizer, então, que um dos temas principais da história política [do antigo Egito -C.F.C.] - os altos e baixos do poder centralizado diante da afirmação provincial - deve ter tido a sua contrapartida econômica na expansão e contração do setor privado, manifestado parcialmente na comercialização local e regional. Temos, aqui, um tema verdadeiramente dinâmico que se expressa em termos econômicos, portanto, a base para uma verdadeira história econômica. (Kemp, 1989: 259-60)

Kemp acha que, nos períodos de centralização monárquica, a maioria da população, vivendo vidas confinadas a aldeias e certos bairros urbanos, teria permanecido alheia à economia e ao mercado privados, e ligada só aos sistemas redistributivos estatais. No entanto, mesmo em tais períodos existiria uma procura privada de certa importância, vinculada a uma "classe significativa de funcionários", cujo nível de vida se apresentava muito acima da estrita subsistência. Os valores sociais de uma sociedade centrada na corte do faraó levavam a que tal classe apresentasse tudo o que tinha como resultante do favor real e de suas atividades pessoais, como funcionários, a serviço do monarca. Mas, na realidade, nem sempre era assim, havendo algum escopo para a iniciativa privada e o enriquecimento por meios próprios, aspectos, no entanto, que só aparecem mais na documentação em períodos de descentralização. Nota-se então, em Kemp, uma visão cíclica da economia do antigo Egito: demanda privada e iniciativa privada conheciam um auge nos períodos de descentralização política e um mínimo (mas sem perderem em tais ocasiões, seja como for, uma real importância) nas fases de centralização monárquica.

O tipo de formalismo praticado por Barry Kemp permite que, ao contrário de formalistas clássicos como Morris Silver, não se veja for- 
çado, para defender seu ponto de vista, a negar especificidades como por exemplo a existência dos sistemas de redistribuição palaciano e templário, não caracterizados por um mercado formador de preços, ao mesmo tempo que afirma que, ainda assim, sempre existia (embora com altos e baixos) uma demanda privada, uma economia privada.

Para o autor que estamos analisando, existe um "fator essencial", de tipo "psicológico", que leva à ambição de querer mais do que um nível de estrita subsistência, nas sociedades providas de excedentes (ou seja, a partir do Neolítico avançado). A agricultura sedentária, ao conduzir a uma ocupação permanente de uma terra determinada e a uma forte ligação com tal terra, oiriginou um "poderoso sentido de direitos territoriais" que, associado à existência de um excedente agrícola, gerou uma "propensão competitiva" no sentido de obter um nível de vida melhor. Não, porém, por meio de um trabalho agrícola extra de parte de quem sofria tal propensão mas, sim, mediante transações (compra e venda) ou, então, por meio do exercício da coerção sobre outros. Isto causou uma mudança irreversível na natureza dos grupos humanos desde o final do Neolítico: de uma soma de agricultores desprovidos de liderança, passou-se a uma sociedade estratificada, hierarquizada, em que uns poucos lideram e a maioria é liderada.

Em outras palavras, mesmo circunscrevendo-se às sociedades posteriores ao Neolítico avançado, o autor trabalha é com mais uma das muitas encarnações da "natureza humana": no caso, um estado de espírito competitivo, criador de uma propensão à acumulação de riqueza e poder. A natureza humana é sempre a-histórica quando postulada em termos universais. Se, em economia, o público (aspectos administrados ou estatais) e o privado (indefectivelmente atado aos mecanismos do mercado, da procura e da iniciativa privadas) não passam de ingredientes que variam somente em suas proporções, do Neolítico avançado até hoje (incluindo, no caminho, o antigo Egito) não há nada de verdadeiramente novo sob o Sol! E, de fato, para Kemp, a nossa economia contemporânea e a dos antigos explicar-se-iam pelos mesmos setores, coexistindo em proporções sem dúvida muito distintas.

Os problemas com as "naturezas humanas" de qualquer tipo, incluindo a versão de Kemp, costumam ser de dois tipos. O primeiro é o empobrecimento radical da importância que se dá ao que cada sociedade ou cultura tem de próprio, de específico: já que, por definição, cada uma delas passa a ser só mais uma manifestação ou ilustração de alguma regra ou lei geral que paira acima da História, dirigindo-a de fora. O segundo é que não resistem a uma análise mais detalhada, razão 
pela qual, a nosso ver, é melhor preferir outra visão da História, na qual a "natureza humana" é algo que só se constrói e destrói na e pela história dos homens, não existindo fora ou acima dela (ou, se existir, será no estrito nível de obviedades triviais: os homens são mortais, comem e bebem, amam, trabalham, comunicam através de signos, etc). No caso específico de Kemp, o "fator essencial" que ele postula esbarra na constatação de que existem e existiram diversas sociedades com agricultura avançada e excedentes que, no entanto, permaneceram mesmo assim em suas estruturas tribais, em lugar de desenvolverem um poder separado do parentesco e uma hierarquia radicalmente diferenciadora do social. Onde foi parar, em casos como estes, aquela "propensão psicológica" à acumulação privada, supostamente universal a partir da agricultura sedentária e do aparecimento de excedentes?

\section{Propostas de interpretação}

Minhas opiniões a respeito do sistema econômico e das idéias econômicas no antigo Egito serão agora exploradas de forma seletiva, concentrando a atenção na problemática do trabalho. Elas podem ser reduzidas às seguintes hipóteses principais:

1) existia indubitavelmente no antigo Egito, desde o terceiro milênio a.C., uma lógica que comandava a administração dos aspectos laborais nas grandes economias públicas (palacianas e templárias) e privadas (propriedades privadas ou de função dos membros da classe dominante);

2) tal lógica pôde conduzir a certo grau de abstração no tocante ao raciocínio aplicado ao trabalho e sua remuneração pelos administradores (escribas);

3) a lógica em questão, no entanto, dista muito de ser semelhante ou análoga à lógica capitalista contemporânea.

Presença de certo grau de generalização e abstração no relativo ao trabalho

Começaremos por esta segunda hipótese listada acima. Sua comprovação também dará um início de apoio às outras hipóteses apontadas.

No antigo Oriente Próximo - região do mundo onde se desenvolveram os mais antigos sistemas de escrita conhecidos - o contar precedeu e preparou o escrever. No início da década de 1970, Denise Schmandt-Besserat publicou resultados de pesquisas suas acerca das origens do uso pré-cerâmico da argila no antigo Oriente Próximo. 
Descobrira que, entre o $\mathrm{IX}^{\circ}$ e o $\mathrm{II}^{\circ}$ milênio a.C, apareciam em múltiplos sítios da Ásia ocidental objetos de barro em forma de esferas, discos, cones, tetraedros e cilindros, feitos com cuidado. Posteriormente, constatou que os mesmos tipos de objetos ocorriam no vale do Nilo, na região do atual Sudão e no Egito, em Abydos, embora com menos variação de formas, posto que somente apareciam esferas e discos. Seus estudos mostraram que se tratava de um sistema de cômputo e registro. Decidiu chamar aqueles objetos por seu nome em língua acádia, abnati. Eles serviam para contar coisas: na Mesopotâmia, cabeças de gado, por exemplo.

$\mathrm{Na}$ Ásia, a variação de forma provavelmente se ligasse à designação de tipos diferentes de coisas computadas: azeite, roupas, animais, etc. Desde fins do $\mathrm{IV}^{\circ}$ milênio a.C, em certos casos os abnati aparecem guardados dentro de bolas ocas e fechadas de cerâmica. De início associados a sítios domésticos, depois serviram para a contabilidade de grandes organizações como templos e palácios. Nas bolas - que também existiam em Abydos, mas com conotação funerária - faziam-se marcas que, segundo a Autora, identificavam os objetos computados. Quando o sistema de marcas - sendo estas os primeiros pictogramas - se aperfeiçoou, a escrita e um sistema de algarismos haviamjá aparecido e os abnati mesmos deixaram de ser necessários.

Um sistema de registro havia, portanto, surgido pela primeira vez uns cinco milênios antes da escrita, estendendo-se segundo princípios análogos a todo o Oriente Próximo, embora não seja possível garantir que as mesmas formas designassem os mesmos objetos em toda aquela extensa região. Se Denise Schmandt-Besserat (1978) estiver certa, foi do sistema em questão que a própria escrita começou a evoluir lentamente. No caso do Egito, pensava-se antes que fora bastante depois da Baixa Mesopotâmia, mas, na atualidade, a tendência é a considerar ter ocorrido muito cedo a invenção da escrita egípcia. (Spencer, 1993: $61-2$ )

A criação de um Estado centralizado por volta de 3100 ou 3000 a.C. na parte egípcia do vale do Nilo criou a necessidade de uma contabilidade envolvendo todo o necessário para administrar e tributar os recursos do país egípcio, entre estes, a força de trabalho. E, com o tempo, chegaram a desenvolver-se mecanismos de generalização e abstração nessa contabilidade.

No vocabulário relativo ao trabalho existente no terceiro milênio a.C, certos termos tinham um significado relativamente preciso e delimitado. Por exemplo, os merwt ou merywt eram trabalhadores estreita- 
mente vinculados a depósitos e locais de trabalho chamados shenau. Outros termos, porém, podiam ser bem mais elásticos. A palavra djet, por exemplo, designava um indivíduo pessoalmente ligado ao serviço de um outro, mas podia aplicar-se a qualquer forma de trabalho, não sendo, então, específica: poderia tratar-se tanto de um humilde trabalho braçal quanto de tarefas de cunho sacerdotal. Mais tarde, sem dúvida, uma mudança semântica limitou o vocábulo à designação só de pessoas obrigadas a trabalhos pesados e braçais. Percebemos, também, projeções ou derivações lógicas no nível do vocabulário administrativo. A palavra isu se aplicava a "prestações" em quaisquer modalidades (receitas, remunerações, preços, etc); por extensão, chamavam-se isuu pessoas obrigadas a trabalhar em troca de uma compensação acertada por contrato, independentemente do tipo de tarefa envolvido. (Menu, 1988; Blackman, $1920)^{2}$

No relativo à remuneração do trabalho, existia a idéia de um "nível do mar", isto é, num sistema dominado, no terceiro milênio a.C. e no seguinte, quanto à remuneração, pelo conceito de ração (aku: literalmente, "aquilo que entra"), definia-se o que se achava ser uma ração adequada, embora tal noção pudesse variar no tempo e segundo as circunstâncias. A melhor documentação a respeito vem do Primeiro Período Intermediário e do início do Reino Médio. Um conto conhecido como "Conto do habitante do oásis" ou "O camponês eloqüente" mostra (B.1, 124-5), em tom sarcástico, rações diárias consideradas insuficientes: um jarro (aproximadamente meio litro) de cerveja e três pães; em outro ponto, menciona o que eram, na época (a $X^{a}$ dinastia dos reis heracleopolitanos), rações vistas como corretas (B.1, 115):"dez pães e dois potes de cerveja". Como notamos no único arquivo privado disponível para o Egito faraônico, datado dos últimos anos do terceiro milênio a.C. ou da primeira metade do século XX a.C, o do sacerdote funerário Hekanakht, que era também pequeno ou médio proprietário rural, a eventual diminuição das rações costumeiras, mesmo em períodos difíceis, implicava um processo de convencimento das pessoas afetadas. ${ }^{3} \mathrm{Nem}$ todas as medidas egípcias são conhecidas (assim, conhecemos a capacidade do jarro, henu, mas não do pote, des). Havia, outrossim, o que poderia ser chamado de "um pão contábil", ou ter-

Ver de Buck, ed. e trad., 1935, vol. I: 94, n 402.e (Encantamento n" 75).

Estudamos este assunto em: Ciro Flamarion Cardoso. Hekanakht: Pujança passageira do privado no Egito antigo. Niterói: Universidade Federal Fluminense, 1993, capítulos 3 e 4 (tese inédita apresentada em concurso para professor titular). 
seset. Era grande a variedade de pães e bolos no antigo Egito e, portanto, o vocabulário que os cobria, mas um tipo determinado, o ter-seset, foi convertido em unidade contábil básica para cálculos envolvendo quaisquer pães. Bernadette Menu tentou calcular o seu peso a partir de certos supostos, chegando a pouco mais de 100 gramas: se estiver certa, os dez pães da ração considerada correta significariam algo como pouco mais de um quilo de pão por dia. (Parkinson, ed., 1991: 23, 21; Menu, 1982: 129-30)

Por constituírem as rações um sistema universal de remuneração, na contabilidade suas unidades básicas - pão e cerveja -, bem como as unidades do próprio trabalho, sofreram um processo de abstração, transformando-se em unidades convencionais e às vezes fictícias. Isto se constata quando as rações de certas pessoas são altas demais, em circunstâncias nas quais não tinham consigo seus familiares e dependentes (e considerando-se que há limites à quantidade de comida que se pode ingerir), por exemplo durante expedições a minas e pedreiras em regiões desérticas: em casos assim, tratava-se de uma contabilidade de direitos adquiridos, a serem efetivados mais tarde. E, não, necessariamente nos mantimentos contabilizados - pão e cerveja - mas sim, eventualmente, em outros bens considerados equivalentes às quantidades especificadas daqueles. Pelo contrário, em certos contextos aparecem também casos de rações diárias assentadas para certas pessoas bem abaixo do nível de subsistência: o que significa que as recebiam pelo trabalho considerado no documento em questão, mas teriam forçosamente de contar com outras fontes de alimentos para sobreviver. O termo hesebu, que designava os homens que trabalhavam, podia também referir-se a unidades abstratas de mão-de-obra. Deste modo, numa dada conta, o assentamento " 20 hesebu" tanto podia significar que vinte homens trabalharam durante um dia quanto que dez homens trabalharam durante dois dias, cinco homens durante quatro dias, etc. (Mueller, 1975; Menu, 1982: 127-30)

O último elemento que traremos aqui para demonstrar a existência de um raciocínio generalizado, genérico e abstrato acerca do trabalho é a questão do que os egípcios chamavam de sau e os gregos traduziram como phylé. Trata-se de um sistema de organização do trabalho em equipes, com conotação temporal: equipes que atuam revezando-se. Interessa-nos o fato de que a lógica implicada por tal sistema - que por muito tempo, erroneamente, sejulgou derivar daquela de uma tripulação de barco - fosse aplicada, no Reino Antigo, tanto a equipes em revezamento (no interior de uma outra organização que tinha caráter 
espacial) no trabalho de corvéia, como por exemplo o que construiu as grandes pirâmides da $\mathrm{IV}^{a}$ dinastia, quanto a equipes de sacerdotes celebrando nos templos, ou a sacerdotes dos cultos funerários privados. Voltaremos em outro contexto aos sau ou phylé. (Roth, 1991)

\section{Lógica presente na administração da mão-de-obra}

O Egito faraônico apresentava quase sempre um nível técnico claramente inferior a da Asia ocidental. No sistema produtivo, tal coisa era compensada pela extrema racionalização do aspecto humano das forças produtivas. Isto pode considerar-se do ponto de vista quantitativo: manipulação e emprego eficientes, quando necessário, de grandes massas humanas agindo em cooperação simples, ou seja, executando paralelamente tarefas análogas; ou qualitativo: mecanismos que garantiam, naquelas atividades que o exigissem, uma divisão e especialização adequadas do trabalho.

Note-se que a opinião oposta foi também defendida. Falando das "economias arcaicas baseadas na armazenagem", ao referir-se às grandes obras públicas empreendidas no Egito e na Mesopotâmia, afirma Stephen Viljoen:

A característica marcante destes trabalhos era que os construtores invariavelmente tentavam atingir o efeito requerido com o máximo uso de materiais - um reflexo do amor, inerente à burocracia, pelo espetacular antes do que pelo estético ou pelo praticamente útil. Os reis se vangloriavam com freqüência da quantidade de materiais usados e do número de trabalhadores empregados. (Viljoen, 1974: 20)

Temos, aqui, a confusão entre o que seria uma motivação não-material e a ausência de cálculo e de racionalização dos recursos disponíveis, que é coisa muito diferente. Qualquer sistema econômico de qualquer tipo tem de racionalizar o emprego dos recursos, independentemente da motivação que estiver por trás da atividade empreendida. Não se deve identificar a formulação ideológica de uma época com a realidade social mesma de então, confundindo a "racionalidade" (ou a falta dela) imputada aos agentes com a "racionalidade do sistema"."

A documentação confirma, para toda a história dinástica do antigo Egito, uma preocupação constante com o controle, a direção e a racionalização do emprego da mão-de-obra disponível, no contexto da

Ver sobretudo: Maurice Godelier, 1971, vol. 2: 192-209; Jon Elster, 1981: 57. 
"corvéia real" como nos demais contextos. Isto se expressa sobretudo numa organização contábil minuciosa - cuja organização, aperfeiçoamento e racionalização ao longo do tempo foram já bem estudados (Megally, 1977: 2-6) - bem como num minucioso enquadramento burocrático dos trabalhadores.

Um dos instrumentos básicos para a administração da mão-de-obra era o censo, pois antes de mais nada era preciso saber com quantas pessoas se podia contar e onde elas estavam. A Pedra de Palermo mostra, já na $I^{\star}$ dinastia, o cômputo "de todas as pessoas dos nomos do Oeste, do Norte e do Leste". E, se os censos que baseavam a formação das equipes para a "corvéia real" não se conservaram, a sua existência é demonstrada pela literatura funerária do Reino Médio. (Breasted, ed., 1906, vol. I: 59; de Buck, 1935, vol. II: 152-3; Cardoso, 1984) O cuidado na regulamentação, controle e direção das tarefas humanas não se limitava, no Reino Antigo, aos trabalhos manuais. Os papiros de Abusir (entre aproximadamente 2390 e 2250 a.C.) detalham com minúcia as obrigações e o desempenho do pessoal sacerdotal do templo funerário do faraó Neferirkare. (Posener-Krieger, 1976: vol. I, 57-9, 108-9, vol. II, 586-7) Sob a quinta dinastia (2465-2323 a.C.), época da verdadeira formação de uma burocracia de Estado no Egito antigo, entre os títulos mais freqüentes dos grandes funcionários achamos os que se traduzem como "diretor da repartição dos agricultores e dos campos na Casa Dupla" (ou seja, no palácio real) e "diretor dos dependentes reais", títulos estes que têm a ver com o controle e o uso da mão-de-obra. (Kanawati, 1980: 1,3,51)

As fontes iconográficas, disponíveis desde o terceiro milênio a.C., em especial os relevos das tumbas privadas, permitem empreender o estudo da divisão e especialização do trabalho ao longo da história do Egito faraônico, no tocante aos grandes domínios pertencentes aos funcionários principais do Estado, ou por eles administrados. Entre a sexta e a décima segunda dinastias, uma documentação adicional que ilumina a divisão do trabalho são os modelos ou maquetes de madeira achados em tumbas.

Se, do nível das forças produtivas, passarmos ao das relações de produção, talvez um bom começo seja a questão das phylé, sobre as quais $\operatorname{diz}$ Ann Roth:

Especialmente importante a respeito é a coleção, deixada inacabada pelo autor ao morrer:Vandier, Jacques. Manuel d'archéologie égyptienne. Paris: Picard, 1952-1978. 6 tomos. 
O conceito de um governo centralizado e por conseguinte de uma burocracia nãojorrou totalmente formado da mente de Narmer (ou de Aha) ${ }^{6}$ mas, sim, desenvolveu-se a partir dos clãs e das sociedades aldeãs do Egito pré-dinástico. A evolução das phylé como instituição ocorreu em paralelo ao desenvolvimento do Estado. Emergindo de seu caráter original como um sistema totêmico de clãs que serviam para identificar e regulamentar as lealdades pessoais e familiares que formam a base de uma sociedade primitiva, desenvolveu-se como um mecanismo burocrático que organizava numerosas pessoas para tarefas tão variadas quanto construir pirâmides ou lavar e vestir a estátua de um rei morto. Durante seu desenvolvimento, o sistema perdeu algo de sua complexidade primitiva e de sua associações com o rei (...) No entanto, [há elementos duradouros que] sugerem que as raízes pré-históricas das instituições sociais primitivas eram mais fundamentais para a sofisticada sociedade egípcia do Reino Antigo do que pareciam. (Roth, 1991: 216)

Nosso acordo com a interpretação assim sugerida para o sistema econômico egípcio, em especial aquele da época das pirâmides (terceiro milênio a.C.) significa desacordo total com esta outra, proposta por Jan Assmann:

... antes do desenvolvimento da sociedade estratificada no final da Pré-História, a sociedade egpícia era indubitavelmente "segmentária" - organizada horizontalmente em clãs e, não, verticalmente em governantes e súditos. Estas estruturas clânicas pré-históricas foram, porém, sistematicamente desmanteladas no Reino Antigo. O rei reinava, com a ajuda de seus funcionários, sobre uma massa indiferenciada. As extremamente fragmentárias fontes para o Reino Antigo das dinastias IV e V não contêm referências de qualquer tipo a estamentos, classes, tribos, clãs e famílias, príncipes locais ou magnatas, nem a centros ou concentrações de poder. O rei e sua clique exerciam um controle absoluto sobre uma massa informe de súditos. (Assmann, 2002: 50-1)

A Autora está se referindo ao faraó fundador da monarquia unificada, sobre cuja identidade há controvérsias: Narmer pertencia à "dinastia zero", enquanto Aha é o primeiro monarca da primeira dinastia. 
Este autor projeta sobre a realidade social egípcia as representações do Estado faraônico sobre si mesmo, especialmente sua reivindicação de um controle absoluto sobre tudo e sobre todos; mas, a contrário do que afirma, as fontes - que sem dúvida são fragmentárias e longe de ideais - , iluminam uma outra realidade social e econômica, abaixo do rei, bem mais estratificada e diferenciada do que ele acredita. Além disso, o Egito nunca deixou de ser uma sociedade baseada em aldeias dotadas de organização interna consistente:

... existe (...) uma forte continuidade entre os agricultores aldeães do Pré-Dinástico e seus similares do período dinástico, posto que a passagem da sociedade pré-dinástica à dinástica foi muito mais organizacional e política do que tecnológica e cultural. O Egito dos faraós permaneceu (...) essencialmente uma sociedade agrária de base aldeã. (Hoffmann, 1980: 17)

Ao tornar-se um reino unificado por volta de 3100 a.C, e por longo tempo ainda depois disso, muitas das estruturas comunitárias, corporativas, de uma cultura profundamente aldeã foram, portanto, preservadas no Egito, onde duraram sem mudanças consideráveis até as grandes transformações técnicas e sociais desencadeadas pelo aumento do contato dos egípcios com a Ásia Ocidental a partir do episódio dos hicsos (séculos XVII-XVI a.C). Foi longuíssimo o processo que conduziu, de uma realidade social de base ainda muito comunitária, a outra, mais marcada pela emergência das famílias conjugais encaradas como unidades econômicas nas aldeias, dos indivíduos e de relações crescentemente mercantis Ainda assim, no Reino Novo (séculos XVIXI a.C), no que restava das estruturas comunitárias mais antigas especialmente os conselhos que funcionavam nas aldeias e povoados do Egito - , mulheres e homens participavam em forma bastante igualitária na gestão dos assuntos comuns. (Cardoso, 1986.a)

Isto posto, quando, pouco antes de 2000 a.C, começamos a ter informações melhores acerca da organização do trabalho no antigo Egito, as relações de produção parecem ter variado principalmente em função da oferta geral de trabalhadores, por sua vez vinculada à agricultura irrigada e seu êxito ou fracasso, conforme os períodos, em assegurar uma base sólida à expansão demográfica. É assim que, nas fases em que, com a diminuição da população (como aconteceu, por exem-

A mesma interpretação, a meu ver correta, acha-se em Trigger, 1983. 
plo, durante o Primeiro Período Intermediário e o início do Reino Médio, na passagem do terceiro para o segundo milênio a.C), as disponibilidades de mão-de-obra tornavam-se inadequadas para uma gestão direta das unidades rurais — opção que se acompanhava do predomínio da remuneração em rações —, difundia-se a exploração indireta, através da intensificação dos arrendamentos em dois níveis: arrendamento de grandes extensões de terras pertencentes ao palácio ou a templos por personagens importantes dotados de posses; subarrendamento destas em parcelas pequenas a camponeses. Ambos os sistemas coexistiram, entretanto, em proporções que não temos como determinar, em vários períodos.

Em paralelo ao que se acaba de descrever, as lógicas complementares do trabalho fixo, atado de fado senão de jure à terra, e das equipes móveis de mão-de-obra - formadas, seja por trabalhadores permanentemente ligados a tal sistema, como no caso dos escravos do Estado (palácio, templos), ${ }^{8}$ seja por trabalhadores convocados para a "corvéia real" por tempo delimitado (configurando um trabalho forçado mas remunerado em rações) - , foram um fator permanente, pelo menos nos segundo e primeiro milênios a.C, da história econômica do Egito farânico.’

\section{Conclusão}

Nossa posição teórica - que é decididamente oposta à dos "formalistas" - depende da constatação de que nunca se vai muito longe, com conhecimento aprofundado das fontes, na modernização da economia egípcia, incluindo nela o assunto do trabalho, sem entrar em choque com certas realidades e constatações.

As diferenças entre as economias antigas e as modernas não eram de grau mas, sim, de natureza. Mesmo na Grécia clássica, na qual, no entanto, as estruturas mercantis e monetárias, bem como a amplitude das transações em geral, haviam avançado muito além de tudo o que conhecera a respeito o Egito dos faraós, é preciso ver como um abuso de linguagem uma tradução de Aristóteles que empregue o termo business como se fosse correspondente à noção de "crematística", quando conviria a expressão "busca da riqueza".

Escravos estes cuja tendência, pelo menos durante o terceiro milênio a.C, parece ter sido diluir-se, a longo prazo, no campesinato egípcio. Cf. Malek, 1986: 91.

'Baseio-me aqui em minha tese inédita: Ciro Flamarion Cardoso. Uma interpretação das estruturas econômicas do Egitofaraônico. Rio de Janeiro: UFRJ, 1987. 
Para o Egito, como para o antigo Oriente Próximo em geral (mesmo no caso da Mesopotâmia), é preciso perceber serem extremamente apertados os limites do que poderia ser uma "reprodução ampliada do capital". Havia razões estruturais, ligadas a como estavam constituídas e funcionavam aquelas sociedades, para que não pudessem surgir verdadeiros mercados de bens e de força de trabalho. No contexto das forças produtivas vigentes, só ínfimas minorias podiam viver muito acima do nível de subsistência, mesmo numa região comparativamente tão rica como o Egito. (Diakonoff, 1969; Diakonoff, org., 1991: capítulos 6 e 8)

\section{Referências bibliográficas}

Assmann, Jan. The Mind of Egypt: history and meaning in the time of the pharaohs. Trad. Andrew Jenkins. New York: Metropolitan Books, 2002.

Blackman, Aylward M.A painted pottery model of a granary in the collection of the late Jeremiah James Colman,Esq., of Carrow House, Norwich. The Journal of Egyptian Archaeology. 6, 1920:206-8.

Bleiberg, Edward.The economy of ancient Egypt.In:Sasson,Jack M. (Org.) Civilizations of the Ancient Near East. New York: Charles Scribner's Sons-Macmillan-Simon \& Schuster, 1995. 4 vols.Vol. 3: 1373-85.

Breasted, James Henry, ed. Ancient Rccords of Egypt. Chicago:The University of Chicago Press, 1906. 6 vols.

Cardoso, Ciro Flamarion. A corvéia no contexto econômico-social do Egito faraônico. História em Cadernos. 2, 1984: 19-25.

Les

communautés villageoises dans l'Égypte ancienne. Dialogues d'Histoire Ancienne. 12, 1986a: 9-31.

Sociedades ,org.

Rio de Janeiro: Campus, 1990.

De Buck, Adriaan, ed. e trad. The Egyptian Coffin Texts. Chicago: The University of Chicago Press, 1935-1961. 7 vols.

Diakonoff, Igor M. Main features of the economy in the monarchies of ancient Western Asia. In: Third International Conference of Economic History. Paris-La Haye: Mouton, 1969. Vol. 3: 13-32.

, org. Early Antiquity. Chicago:The University of Chicago Press, 1991.

Elster, Jon. La motivación de los agentes económicos en el pasado. In:Topolski, Jerzy et alii. Historia Económica: Nuevos Enfoques y Nuevos Problemas. Trad.J.P. Barnadas. Barcelona: Crítica, 1981: 51-60.

Godelier, Maurice. Rationalité et irrationalité en économie. Paris: François Maspero, 1971. 2 vols.

Hoffmann, Michael. Egypt Before the Pharaohs: The prehistoric foundations of Egyptian civilization. London-Henley: Routledge \& Kegan Paul, 1980. 
Janssen, Jacob J. Commodity Prices from the Ramesside period. Leiden: Brill, 1975.

Gift-giving in ancient Egypt as an economic feature. The Journal of Egyptian Archaeology. 63, 1982: 253-8.

Kanawati, Naguib. Governmental Reforms in Old Kingdom Egypt. Warminster: Aris \& Phillips, 1980 .

Kemp, Barry J. Old Kingdom, Middle Kingdom and Second Intermediate Period c. 2686-1552 BC. In:Trigger, Bruce G. et alii. Ancient Egypt:A Social History. Cambridge: Cambridge University Press, 1983: 71-182. 1989.

Ancient Egypt: Anatotny of a Civilization. London-New York: Routledge,

Liverani, Mario. II modo di produzione. In: Moscati, Sabatino, org. L'alba delia civiltà. Torino: UTET, 1976. 3 vols.Vol. 2: 2-126.

Communautés rurales dans la Syrie du II $^{e}$ millénaire A.C. In:Théodoridès, Aristide et alii. Les communautés rurales. Paris:Dessain et Tolra, 1983:147-85.

The collapse of the Near East regional system at the end of the Bronze Age. In: Rowlands, Michael et alii, orgs. Centre and Periphery in the Ancient World. Cambridge: Cambridge University Press, 1987: 66-73.

Malek, Jaromír. In the Shadow of the Pyramids: Egypt during the Old Kingdom. London: Orbis, 1986.

Megally, Mounir. Notions de comptabilité à propos du Papyrus E. 3226 du Musée du Louvre. Le Caire: Institut Français d'Archéologie Orientale du Caire, 1977.

Menu, Bernadette. Recherches sur l'histoire juridique, économique et sociale de l'ancienne Egypte. Versailles: edição da Autora, 1982.

Une approche de la notion de travail dans l'Ancien Empire égyptien. In: Aliam, S. et alii. Stato, Economia e Lavoro nel Vicino Oriente antico. Milano: Franco Angeli, 1988:94-110.

Moran, William L., ed. e trad. The Amarna Letters. Baltimore-Londom The Johns Hopkins University Press, 1992.

Moscati, Sabatino, org. L'Alba della Civiltà. Torino: UTET, 1976. 3 vols.

Mueller, Dieter. Some remarks on wage rates in the Middle Kingdom.Journal of Near Eastern Studies. 34, 1975: 249-63.

Parkinson, R. B., ed. The Tale of the Eloquent Peasant. Oxford: Griffith Institute, 1991.

Polányi, Karl et alii, orgs. Comercio y Mercado en los Imperios Antiguos. Trad. Alberto Nicolás. Barcelona: Labor, 1976.

Posener-Krieger, Paule. Les archives du templefunéraire de Néferirkare-Kakai (Les papyrus d'Ahousir). Le Caire: Institut Français d'Archéologie Orientale du Caire, 1976. 2 vols.

Rolh, Ann Macy. Egyptian Philes in the Old Kingdom: The evolution of a system of social organization, Chicago:The Oriental institute, 1991.

Schmandt-Besserat, Denise.An early recording system in Egypt and the ancient Near East. In: Schmnandt-Besserat, Denise, org. Immortal Egypt. Malibu: Undena, 1978: 5-12. 
Silver, Morris. Economic Structures of Antiquity. Westport-London: Grenwood Press, 1986.

Snell, Daniel C. Life in the Ancient Near East. New Haven-London: Yale University Press, 1997.

Spencer, A. J. Early Egypt: The Rise of Civilization in the Nile Valley. London: British Museum Press, 1993.

Trigger, Bruce G.The rise of Egyptian civilization. In:Trigger, Bruce G. et alii. Ancient Egypt: A Social History. Cambridge: Cambridge University Press, 1983: 2-70.

Viljoen, Stephen. Economic Systems in World History. London: Longman, 1974.

Zaccagnini, Carlo. Modo di produzione asiático eVicino Oriente antico:Appunti per una discussione. Dialoghi di Archeologia. 3, 1981: 3-65.

Aspects of ceremonial exchange in the Near East during the late second millenium BC. In: Rowlands, Michael et alii, orgs. Centre and Periphery in the Ancient World. Cambridge: Cambridge University Press, 1987: 57-65. 